\title{
Patient needs and preferences for herb-drug-disease interaction alerts: a structured interview study
}

\author{
Carrie M. Christensen ${ }^{1 *}$, Rebecca S. Morris ${ }^{1}$, Seraphine Chepkemoi Kapsandoy ${ }^{1}$, Melissa Archer ${ }^{2}$, Jinqiu Kuang ${ }^{1}$, \\ Laura Shane-McWhorter ${ }^{3}$, Bruce E. Bray ${ }^{1}$ and Qing Zeng-Treitler ${ }^{1}$
}

\begin{abstract}
Background: While complementary and alternative medicine (CAM) is commonly used in the United States and elsewhere, and hazardous interactions with prescription drugs can occur, patients do not regularly communicate with physicians about their CAM use. The objective of this study was to discover patient information needs and preferences for herb-drug-disease interaction alerts.

Methods: We recruited 50 people from several locations within the University of Utah Hospital to participate in this structured interview study. They were asked to provide their preferences for the herb-drug-disease interaction alerts. Qualitative methods were used to reveal the themes that emerged from the interviews.

Results: Most participants reported they had previously used, or they were currently using, CAM therapies. The majority had made the effort to inform their healthcare provider(s) about their CAM usage, although some had not. We found that most respondents were interested in receiving alerts and information about potential interactions. Many preferred to receive the alerts in a variety of ways, both in person and electronically.

Conclusions: In addition to conventional medicine, many patients regularly use complementary and alternative therapies. And yet, communication between patients and providers about CAM use is not consistent. There is a demand for interventions in health care that provide timely, integrative communication support. Delivering the herb-drug-disease alerts through multiple channels could help meet critical patient information needs.
\end{abstract}

Keywords: Alerts, Complementary and alternative medicine, Structured interview study

\section{Background}

According to the National Center for Complementary and Integrative Health (NCCIH), "Many Americans-more than $30 \%$ of adults and about $12 \%$ of children-use health care approaches outside of mainstream Western, or conventional, medicine." "Complementary" medicine uses methods that are outside of the mainstream, together with conventional medicine. When an approach is used in place of conventional medicine it is called "alternative." [1].

CAM use may include dietary supplements or other products taken by mouth. These dietary supplements

\footnotetext{
* Correspondence: c.m.christensen@utah.edu

'Department of Biomedical Informatics, University of Utah School of Medicine, 421 Wakara Way, Suite 140, Salt Lake City, UT 84108, USA Full list of author information is available at the end of the article
}

contain ingredients (such as vitamins, minerals, herbs or botanicals, amino acids, concentrates, metabolites, constituents, or extracts) that are intended to supplement an individual's diet [2]. Some supplements ensure you will get an adequate amount of essential minerals and nutrients in your diet, for instance, while others may contain properties that reduce your disease risk. They may be used together with, or in place of, conventional medications.

The use of CAM is widespread among relatively healthy people, as well as among those who suffer from disease. A survey of 20,000 individuals indicated that supplements are used by $49 \%$ of the United States population (53\% of females and $44 \%$ of males) [3]. Approximately $\$ 15$ billion dollars is spent per year on dietary supplements [4]. In the United States, approximately 4 out of every 10 
adults, and 1 out of 9 children, use some form of CAM [5]. CAM use is most prevalent in women, and individuals with higher incomes and higher levels of education [5].

The NCCIH currently sorts most complementary health approaches into one of two subgroups, "natural products" or "mind and body practices." A survey from 2007 reported that U.S. adults commonly used nonvitamin, nonmineral (NVNM) dietary supplements (17.7\%), such as echinacea, St.John's wort, or ginseng, and various mind body practices such as deep breathing exercises (12.7\%), meditation (9.4\%), chiropractic or osteopathic manipulation (8.6\%), massage (8.3\%), and yoga (6.1\%) [5].

Many CAM products and practices are believed to be safe for consumers, although "natural products" can interact with prescription medications to negatively impact health outcomes for patients [6]. There are many known interactions between supplements and conventional medications which present health risks [7]. For instance, ginseng is known to interact with warfarin and may increase risk of breakthrough thromboembolic events [7]. St John's wort may interact with certain medications (antihypertensives, statins, oral contraceptives, and anticoagulents like warfarin) lowering serum concentrations to sub-therapeutic levels, and thus diminishing the benefits conferred by those medications [7].

It has been estimated that only $33.4 \%$ of the general public informs health care providers about their use of supplements [8]. Our previous study showed that patientreported CAM usage rates and provider estimates are disparate [9]. A concern is that many individuals are taking products that are contraindicative or seriously endangering to patients with conditions such as cardiovascular disease [10] and diabetes [11].

This paper describes a structured interview study that was conducted to gain insight into preferences for an alert system we are developing that will inform patients and physicians of imminent herb-drug-disease interactions. Alerts and reminders have been variably successful informatics interventions in healthcare [12-15], though drug-drug interaction alerts have generally been directed at providers rather than patients. Herb-drug-disease alerts are a fairly new domain for research and development. We need to understand the patient-centered information needs and preferences of the target population in order to design effective alerts.

\section{Methods}

We recruited a convenience sample of accessible participants from several University of Utah locations until we felt the sample group included a fair representation of underserved minorities and a sufficient number was reached to reveal patterns and themes associated with preferences for CAM interaction alerts. Qualitative methods were used to reveal the themes which emerged from the interviews, and we used qualitive methods to interpret and integrate the findings of this interview study.

The study was pre-approved by the University of Utah Institutional Review Board (IRB). We included participants age 21 or older, with the ability to speak and read English. Members of the University of Utah Health Care System such as physicians, physician assistants, nurse practitioners, students, and administrative staff were excluded from the study.

The research team explained the purpose of the interview to those interested in participating in the study. A short introduction was also provided explaining the prevalence of CAM use and the potential for CAM treatments to interact with conventional medications and serious health conditions. Those who agreed to take part in the study read the consent form and gave their consent by verbal agreement. Participants then filled out a demographic questionnaire. Names or other personal identifiers were not recorded.

During the interviews, research staff members asked a series of questions according to the study script (see Additional file 1). The questions were either multiple choice or short answer format. The answers from study participants were recorded in handwritting by the staff. In order to ensure that all interviews were conducted in a standardized format, a staff training session was held before patient recruitment.

Notes from the interviews were transcribed into an electronic datasheet for analysis. Descriptive statistics were generated for the demographic information and participant responses to the multiple choice questions. Short answer responses were coded to refine categories, themes, and concepts. Two researchers worked to complete the qualitatitive analysis. The qualitatitive transcripts were individually and jointly analyzed to develop a coding manual of themes and definitions. The qualitative data was processed using content analysis techniques and Atlas ti software, version 7.0. Their work was checked for interrater reliability and validity.

\section{Results}

In this convenience sample of 50 respondants (see Additional file 2), the demographic data showed that there were more white $(66 \%)$ and female $(64 \%)$ participants than there were non-white (34\%) and male (36\%). Most of the participants $(80 \%)$ had more than a 12 th grade education and (88\%) spoke English as their first language. The majority of respondents were 30 to 59 years of age. Compared to the general U.S. population, our study sample had achieved relatively higher levels of education, yet they were similar in racial diversity [16]. Table 1 shows the demographic data collected from the study participants. 
Table 1 Participant demographics by CAM use

\begin{tabular}{|c|c|c|c|}
\hline & Total $(N=50)$ & CAM users $(N=43)$ & Non-CAM users $(N=7)$ \\
\hline \multicolumn{4}{|l|}{$\overline{\text { Sex- no. (\%) }}$} \\
\hline Men & $18(36)$ & $16(37.21)$ & $2(28.57)$ \\
\hline Women & $32(64)$ & $27(62.79)$ & $5(71.43)$ \\
\hline \multicolumn{4}{|l|}{ Age- no. (\%) } \\
\hline $21-29$ years old & $6(12)$ & $5(11.63)$ & $1(14.29)$ \\
\hline 30-39 years old & $11(22)$ & $10(23.26)$ & $1(14.29)$ \\
\hline 40-49 years old & $8(16)$ & $8(18.60)$ & $0(0)$ \\
\hline 50-59 years old & $12(24)$ & $10(23.26)$ & $2(28.47)$ \\
\hline 60-69 years old & $7(14)$ & $5(11.63)$ & $2(28.57)$ \\
\hline 70-79 years old & $4(8)$ & $3(6.98)$ & $1(14.29)$ \\
\hline $80+$ years old & $1(2)$ & $1(2.33)$ & $0(0)$ \\
\hline Unknown & $1(2)$ & $1(2.33)$ & $0(0)$ \\
\hline \multicolumn{4}{|l|}{ Ethnicity- no. (\%) } \\
\hline Hispanic & $7(14)$ & $7(16.28)$ & $0(0)$ \\
\hline Non-Hispanic & $43(86)$ & $36(83.72)$ & $7(100)$ \\
\hline \multicolumn{4}{|l|}{ Race- no. (\%) } \\
\hline White & $33(66)$ & $27(62.79)$ & $6(85.71)$ \\
\hline Black & $7(14)$ & $7(16.28)$ & $0(0)$ \\
\hline Other & $10(20)$ & $9(20.93)$ & $1(14.29)$ \\
\hline \multicolumn{4}{|l|}{ Education- no. (\%) } \\
\hline $12^{\text {th }}$ Grade & $10(20)$ & $7(16.28)$ & $3(42.86)$ \\
\hline Above $12^{\text {th }}$ Grade & $40(80)$ & $36(83.72)$ & $4(57.14)$ \\
\hline \multicolumn{4}{|l|}{ Language- no. (\%) } \\
\hline English & $44(88)$ & $37(86.05)$ & $7(100)$ \\
\hline Non-English & $6(12)$ & $6(13.95)$ & $0(0)$ \\
\hline
\end{tabular}

We found many subjects (86\%) had previously used or currently use complementary or alternative medicine. This prevalence is higher than what was reported by a national survey [5], yet consistent with our previous study in Utah [11]. Table 2 displays the most commonly used supplements or alternative medicine therapies. Table 3 allows for the comparison between the total number of CAM therapies or supplements reported by all 50 respondents and use of multivitamins and other vitamin or mineral supplements.

\section{Communication with medical providers about CAM use} A majority of the respondents who had used complementary or alternative medicine and some also told their doctor or other health care provider(s) about their CAM use. Being asked for the information by health care professionals (40.7\%) and caution/safety concerns (25.9\%) were the two main reasons the participants gave for having told about their CAM use. Seven themes were identified in all:
Table 2 Supplement or alternative medicine therapy and frequency of use $(N=43)$

\begin{tabular}{ll}
\hline Percent use & \\
\hline $72.1 \%$ & $\begin{array}{l}\text { Vitamin or mineral supplements other than } \\
\text { multivitamins (Vitamin C, Niacin, Vitamin D, etc.) }\end{array}$ \\
$53.5 \%$ & Multivitamin \\
$23.3 \%$ & Fish oil or omega-3 \\
$14.0 \%$ & Probiotics \\
$14.0 \%$ & Over-the-counter medications (Aspirin, Tylenol, etc.) \\
$11.6 \%$ & Glucosamine or chondroitin sulfate \\
$9.3 \%$ & Tea \\
$7.0 \%$ & CoQ10 \\
$7.0 \%$ & Flax seed \\
$60.5 \%$ & Other supplements or alternative medicine therapies \\
& (wellness formula from health food store, vegi protein \\
& powder, laxative, etc.) \\
\hline
\end{tabular}


Table 3 Number of CAM therapies or supplements by multivitamin and other vitamin or mineral supplement use

\begin{tabular}{|c|c|c|c|c|c|}
\hline \multirow[t]{2}{*}{$\begin{array}{l}\text { Total no. of CAM } \\
\text { therapies or supplements }\end{array}$} & \multirow{2}{*}{$\begin{array}{l}\text { Any } \\
\text { CAM } \\
\text { use }\end{array}$} & \multicolumn{2}{|c|}{$\begin{array}{l}\text { Uses vitamin or mineral supplements } \\
\text { (other than multivitamins) }\end{array}$} & \multicolumn{2}{|c|}{ Uses multivitamins } \\
\hline & & Yes & No & Yes & No \\
\hline 0 & $7(14.0)$ & $0(0.0)$ & $7(14.0)$ & $0(0.0)$ & $7(14.0)$ \\
\hline 1 & $7(14.0)$ & $2(4.0)$ & $5(10.0)$ & $3(6.0)$ & $4(8.0)$ \\
\hline $2-3$ & $12(24.0)$ & $5(10.0)$ & $7(14.0)$ & $6(12.0)$ & $6(12.0)$ \\
\hline $4-5$ & $9(18.0)$ & $9(18.0)$ & $0(0.0)$ & $4(8.0)$ & $5(10.0)$ \\
\hline$\geq 6$ & $15(30.0)$ & $15(30.0)$ & $0(0.0)$ & $10(20.0)$ & $5(10.0)$ \\
\hline Total & $50(100)$ & $31(62.0)$ & $19(38.0)$ & $23(46.0)$ & $27(54.0)$ \\
\hline
\end{tabular}

1) Health care professional requested the information: RESPONDENT 24. Because he asked. I don't want anything to interact. I always tell.

2) Caution/safety concerns:

RESPONDENT 25. I have a list of everything I take because it could interact with my prescription.

3) Knowing that it was important information: RESPONDENT 34. Because I am a medical professional and I know it's important.

4) Desire to consult with a physician on current medical problem(s):

RESPONDENT 39. Yes, because she [doctor] could see the change in me and I wanted to share. Everything turned around. I was going to do chemotherapy and have lymph nodes removed. The body has its own consciousness and healing.

5) Mistrust of medical doctors or feeling that the information is not relevant:

RESPONDENT 36. Sometimes, but I do not list it on my forms of medications. I tell them, depending on how I feel, if it is pertinent to my treatment. For example, if I am talking about having cramps I tell them about my digestive enzymes.

6) Health concerns related to comorbidities and/or medications:

RESPONDENT 35. I make them aware because I have prescription medicines.

7) Influence of a family member:

Table 4 When participants informed provider of CAM use $(N=27)$

\begin{tabular}{ll}
\hline & Frequency \\
\hline When they started taking them & $29.6 \%$ \\
When they stopped taking them & $7.4 \%$ \\
When they suspected a problem & $11.1 \%$ \\
When they filled out their history at the doctor's visit & $85.2 \%$ \\
$\begin{array}{l}\text { Other (examples include: randomly, at health care provider } \\
\text { visit, when concerned about potential overdose, when }\end{array}$ & $37.0 \%$ \\
$\begin{array}{l}\text { filling prescriptions, and when they wanted to be on } \\
\text { supplements) }\end{array}$ & \\
\hline
\end{tabular}

RESPONDENT 37. My wife told me to. I never would have thought about telling them before.

Potential interactions are most likely to occur when patients start or stop taking supplements or alternative medicine. These 27 participants informed their providers of their CAM usage at various times as shown in Table 4. The most common occasion during which this information was conveyed was when they filled out a medical history form at a doctor appointment (85.2\%).

\section{Barriers to communication with providers about CAM use} Of the 43 respondents who had used complementary or alternative medicine, 16 did not inform their doctor or other health care provider(s). Three major reasons were identified:

1) Never asked about their use of supplements or alternative medicine:

RESPONDENT 21. They have never asked. I didn't think it was a big deal.

2) Perceived unimportance or irrelevance RESPONDENT 44. I guess I just never saw it as important.

3) Partially informed health care provider of supplement use:

RESPONDENT 41. Yes, she (doctor) is aware of the vitamin D. Hasn't told her about vitamin B yet.

Half of the participants did not tell their doctor because they viewed the information as unimportant or irrelevant. People are more likely to tell their providers if they are asked for the information, yet only $52 \%$ of the study population had ever been asked. If CAM information is inconsistently collected by providers. Study participants who had been asked by a health care professional about their CAM use in the past were asked to give examples of when this occurred. Many respondents said that health care professionals had asked them verbally or 
through questionnaires at intake. Others were asked when discussing medication history, or upon being prescribed a new medication. Some told their physicians during a clinical consult regarding a possibly-related health concern.

If asked about their supplement or alternative medicine use, 49 out of 50 participants said that they would tell their providers. This reveals a strong willingness on the part of consumers to share their CAM usage information with providers. However, the participants were not completely confident that their providers would use the information to enhance their medical care. Only half of the respondents felt that their providers would take their CAM usage into account when treating or managing their illness. The alerts we provide could be useful for conveying critical information, hopefully without overwhelming the patient.

\section{Needs and preferences for interaction alerts}

Most of the interview respondents said that they were interested in receiving information about potential interactions with their prescriptions and other medicines, including herbal supplements. Their needs and preferences were categorized into the following groups:

1) Need for general information about ingredients, effects and interactions:

RESPONDENT 4. The more information the better. If you don't know about the potentials you could be increasing/decreasing the potency and interactions.

2) Caution/safety concerns: RESPONDENT 1. I don't want to get sicker than I already am. A lot can interact and kill you, alternative and otherwise.

3) Mistrust of healthcare provider(s): RESPONDENT 37. I would like to know that even if it's missed by the doctor or pharmacy I would still get the information and bring it to someone's attention; fail-safe type thing.

4) Financial concerns: RESPONDENT 28. Well, what if I find out it's just a waste of money [and] cancelling out the effect of another medicine.

5) Desire to consult with a physician:

RESPONDENT 39. Yes, I would want to know what the doctor thought, to get another perspective. [She] doesn't want to limit self. Has seen miracles happen. 46 out of 50 interview participants were interested in the information.

The most common themes were general information needs and caution/safety concerns. Acceptable methods by which participants wished to receive information alerting them to potential interactions are listed in Table 5 . The participants were asked if they wanted to be told about all possible interactions, or only the most serious.
Table 5 Participant answers to multiple choice question about preferred methods to receive interaction alerts $(N=50)$

\begin{tabular}{ll}
\hline & Frequency \\
\hline Directly from their doctor & $76 \%$ \\
At a kiosk in the waiting room at doctor visits & $44 \%$ \\
Through a smart phone application & $58 \%$ \\
Through their personal health record (PHR) & $64 \%$ \\
At the pharmacy & $74 \%$ \\
By print or email & $76 \%$ \\
Other (answers included: written, verbal, phone, face-to-face, & $28 \%$ \\
website, TV in waiting room, software program for PC, & \\
during annual physical exam, email only, and at home) &
\end{tabular}

39 participants $(78 \%)$ chose to be told about all possible drug interactions. The remaining 11 wanted to be informed about serious drug interactions only.

The participants considered life-threatening interactions to be serious, as well as those causing permanent organ damage. Vision or blood pressure changes, urinary retention, allergic reactions, and interactions causing problems with prescriptions and other drugs were also considered serious. The preferences of those who wanted to know about all possible drug interactions have been categorized into the following 5 groups:

1) To be well informed: RESPONDENT 18. You want all information, every detail. If you don't get it all you get poor information.

2) Awareness of possible interactions and their severity levels:

RESPONDENT 33. When you say that I see a scale, e.g., yellow, green, red. I want to see a scale/grading scale of severity so I can get an idea of what I am dealing with.

3) Decision support:

RESPONDENT 35. Because I want to know about my health so I can make a good decision.

4) To avoid interactions:

RESPONDENT 4. Concerned about interactions that lessen or increase the potency of the given dosage. That is, if I'm on X mg of an antidepressant, maybe the herbal medication will decrease the effectiveness. [...].

5) Mistrust of clinicians: RESPONDENT 14. [He] plans ahead for different disease contingencies. Looks ahead, feels doctors use patients as guinea pigs. [...]. If you're considered a burden to the system, they don't care. [He] stays away from herbal medications because doesn't know what they'll do to him personally.

Of these five themes, the largest group of respondents preferred to know about all possible interactions in 
order to be well informed (category 1), followed by those who wanted the information for decision support (category 3), and those who wanted to be aware in order to consider the severity levels (category 2). The data listed in Table 6 displays the respondents' preferences upon being asked, "What information would you like to receive regarding the possible drug interaction?" Over half wanted to receive all available information. One person indicated they did not wish to receive any information about possible interactions. The interview participants were asked to describe the reasons why they selected to receive the information they did. Their responses were categorized as follows:

1) Safety: RESPONDENT 15. [...]. I don't want to have a stroke. I would be really interested. Need to know all possible after-effects. [...]. I am chemically sensitive.

2) Increased knowledge:

RESPONDENT 11. To get knowledge about the medications, to see if it made [them] stronger.

3) To be proactive:

RESPONDENT 31. Being proactive about our health.

4) Consult with primary care provider:

RESPONDENT 8. Because it would help to know when you were going to the doctor, so they wouldn't give you something you would have a bad reaction to.

5) Mistrust of clinicians, pharmacy, drugs not approved by the FDA:

RESPONDENT 40. Doctors should not act like God or something. They should listen to patients and take their advice on what works for their bodies. [...].

6) To avoid death: RESPONDENT 17. Because I don't want to die.

7) Personalization:

Table 6 Patient preferences regarding types of information they would like to receive $(N=50)$

\begin{tabular}{lc}
\hline & Frequency \\
\hline $\begin{array}{l}\text { Taking St. John's wort with warfarin frequently results in an } \\
\text { interaction }\end{array}$ & $82 \%$ \\
$\begin{array}{l}\text { Taking St. John's wort with warfarin can cause a serious } \\
\text { reaction. }\end{array}$ & $88 \%$ \\
$\begin{array}{l}\text { We strongly recommend that you inform your doctor and } \\
\text { consider not taking St. John's wort }\end{array}$ & $90 \%$ \\
$\begin{array}{l}\text { You are at greater risk because you have high blood } \\
\text { pressure and have experienced an episode of bleeding }\end{array}$ & $94 \%$ \\
$\begin{array}{l}\text { Taking St. John's wort with warfarin can cause you to have } \\
\text { a stroke }\end{array}$ & $96 \%$ \\
$\begin{array}{l}\text { Taking St. John's wort with warfarin decreases the clotting } \\
\text { ability of your blood }\end{array}$ & $88 \%$ \\
$\begin{array}{l}\text { A recent article described two cases where patients who } \\
\text { were taking St. John's wort with warfarin had strokes }\end{array}$ & $62 \%$ \\
\hline
\end{tabular}

RESPONDENT 15. [I] especially like to be told things special for me. [...].

The interviews we conducted gathered information on patient needs and preferences concerning CAM interaction alerts. There was a marked desire for information on the part of consumers. Almost all participants (92\%) expressed an interest in receiving information on interaction alerts and most (78\%) wanted to be told about all possible drug interactions (in addition to learning about the most serious interactions). Interview participants wished to receive alerts in a variety of ways, in-person and electronically.

\section{Discussion}

\section{Significance}

The structured interview study we conducted elicited patients' needs and preferences for CAM herb-drugdisease interaction alerts. We observed strong consumer demand for the interaction alerts. Most expressed an interest in receiving information on potential interactions, and most wanted to be told about all possible drug interactions, as opposed to only the most serious interactions. Similarly, over half of the respondents elected to receive all of the seven types of information we presented regarding possible drug reactions. Participants also preferred to receive the interaction alerts in a variety of ways, electronically as well as in personally. The alert system we envision is inclined toward redundancy. Patients should get information from their doctors directly, as well as from the alert messages they receive through a convenient device such as their smart phone.

Several previous studies have investigated CAM useage in different patient populations and patient/physician communication about CAM use. We found that supplements were used commonly by interview participants, and there is a deficiency in communication between patients and providers about it. These findings are consistent with the prior research. Patient perspectives on herb-drugdisease interaction alerts have not been investigated specifically. Our research group did conduct a systematic literature review on alerts and reminders targeting patients (Perri-Moore S [17]). While alerts are still rare in the literature, patient reminders are generally received with positive results.

\section{Limitations}

This moderately sized qualitative study elicited the interests of participants from a patient-centered perspective. We asked the interview participants about hypothetical alert situations; their preferences for interaction alerts in this study may not be completely true to real-life circumstances. For instance, a small number of patients might receive excessive alerts and experience alert fatigue (like physicians). Another concern is that directly 
alerting patients might cause them to act in ways that are dangerous to their health; they could elect to stop taking their prescription drug, for instance, instead of the problematic supplement. In this interview study we did not explore the actions taken following alerts. It is recommended that the interaction alerts we propose always remind patients to consult with their physicians.

\section{Future work}

The findings of this study will inform our ongoing project to alert patients of potentially harmful interactions. In the near future we will explore the actions taken by patients (and providers) following the herb-drug-disease interaction alerts. We will design our system to meet patient needs, such as providing comprehensive information through a variety of communication channels.

Consistent with prior literature on the subject, we observed a high prevalence of CAM use, and communication between patients and providers on the subject was inconsistent. This study highlights the need to develop informative interventions that will hold interest and protect patients by preventing harmful interactions. The study findings indicate that patients are willing to partner with physicians regarding decision-making about CAM use, though physicians are not fully trusted to always take CAM usage into account when creating a treatment plan. Providing alerts to inform patients of potential herb-drug-disease interactions, and delivering them through several methods, would help meet patient information needs.

\section{Conclusions}

Consistent with prior literature on the subject we observed a high prevalence of CAM usage in the interview study population, and communication with providers about such use was unreliable. The study findings indicated that patients would be willing to partner with their physicians in decision-making about CAM, although physicians are not fully trusted to take CAM useage into consideration. As we move toward integrative health, there is a need in the community to develop interventions, alerts, which will inform patients and warn them of possible conflicts with their prescriptions and their complementary and alternative medicines.

\section{Additional files}

Additional file 1: Participant Data Collection Sheet and Interview Script.
(PDF $165 \mathrm{~kb})$
Additional file 2: Patient Questionnaire. (XLSX $31 \mathrm{~kb})$

\section{Abbreviations}

CAM: Complementary and Alternative Medicine; IRB: Institutional Review Board; NCCIH: National Center for Complementary and Integrative Health; NVNM: Nonvitamin, Nonmineral

\section{Acknowledgements}

This information is not relevant.

\section{Funding}

This project was supported by National Institute of Health $(\mathrm{NIH})$ grant numbers 5R01LM011334 and 1R01AT006548.

Availability of data and materials

The dataset supporting the conclusions of this article is include within the article (and its additional files).

\section{Authors' contributions}

All authors participated in the study design, data acquisition, analysis, interpretation, and manuscript drafting. QZT was the Principal Investigator of the study design and data analysis and was responsible for the integrity of the research as a whole. CMC led the interview study and data collection. RSM and CMC prepared the manuscript. RSM and SCK analyzed the data. $M A, J K, L S M$, and CMC participated in the analysis and interpretation of the data. BEB and LSM provided clinical expertise in study design and data analysis. All authors read and approved the final manuscript.

\section{Competing interests}

The authors declare that they have no competing interests.

\section{Consent for publication}

This information is not relevant.

\section{Ethics approval and consent to participate}

This project was reviewed by the Institutional Review Board (IRB) at the University of Utah to ensure compliance with ethical standards and local, state, and federal laws. The IRB reference number is 61967.

\section{Author details}

'Department of Biomedical Informatics, University of Utah School of Medicine, 421 Wakara Way, Suite 140, Salt Lake City, UT 84108, USA. ${ }^{2}$ Drug Regimen and Review Center, University of Utah College of Pharmacy, Salt Lake City, UT, USA. ${ }^{3}$ Department of Pharmacotherapy, University of Utah College of Pharmacy, Salt Lake City, UT, USA.

Received: 7 August 2015 Accepted: 8 February 2017 Published online: 19 May 2017

\section{References}

1. Complementary, Alternative, or Integrative Health: What's In a Name? https://nccih.nih.gov/health/integrative-health Accessed 20 Dec 2015.

2. Administration USFDA. Dietary Supplements. http://www.fda.gov/food/ dietarysupplements/. Accessed 13 Oct 2013.

3. Bailey RL, Gahche JJ, Lentino CV, et al. Dietary supplement use in the United States, 2003-2006. J Nutr. 2011;141(2):261-6.

4. Nahin RL, Barnes PM, Stussman BJ, Bloom B. Costs of complementary and alternative medicine (CAM) and frequency of visits to CAM practitioners: United States, 2007. Natl Health Stat Rep. 2009;18:1-14.

5. Barnes PM, Bloom B, Nahin RL. Complementary and alternative medicine use among adults and children: United States, 2007. Natl Health Stat Rep. 2008:12:1-23

6. Tachjian A, Maria V, Jahangir A. Use of herbal products and potential interactions in patients with cardiovascular diseases. J Am Coll Cardiol. 2010;55(6):515-25

7. Izzo AA, Ernst E. Interactions between herbal medicines and prescribed drugs: an updated systematic review. Drugs. 2009;69(13):1777-98.

8. Kennedy J. Herb and supplement use in the US adult population. Clin Ther. 2005;27(11):1847-58

9. Scarton LA, Zeng Q, Bray BE, Shane-McWhorter L. Feasibility and potential benefit of collecting Complementary and Alternative Medicine data through a computerized patient interview. AMIA Ann Symp Proc. 2011;2011:1217-23.

10. Krasuski RA, Michaelis K, Eckart RE. The cardiovascular patient's perceptions of complementary and alternative medicine. Clin Cardiol. 2006;29(4):161-4.

11. Nahin RL, Byrd-Clark D, Stussman BJ, Kalyanaraman N. Disease severity is associated with the use of complementary medicine to treat or manage type-2 diabetes: data from the 2002 and 2007 National Health Interview Survey. BMC Complement Altern Med. 2012;12:193. 
12. van der Sijs H, Aarts J, Vulto A, Berg M. Overriding of drug safety alerts in computerized physician order entry. J Am Med Inform Assoc. 2006;13(2): 138-47.

13. Weingart SN, Toth M, Sands DZ, Aronson MD, Davis RB, Phillips RS. Physicians' decisions to override computerized drug alerts in primary care. Arch Intern Med. 2003;163(21):2625-31.

14. Phansalkar S, Desai AA, Bell D, et al. High-priority drug-drug interactions for use in electronic health records. J Am Med Inform Assoc. 2012;19(5):735-43.

15. Duke JD, Bolchini D. A successful model and visual design for creating context-aware drug-drug interaction alerts. AMIA Ann Symp Proc. 2011; 2011:339-48.

16. Measuring America-People, Places, and Our Economy. http://www.census.gov/.

17. Perri-Moore S, Kapsandoy S, Doyon K, Hill B, Archer M, Shane-McWhorter L, Bray BE, Zeng-Treitler Q. "Automated Alerts and Reminders Targeting Patients: A Review of the Literature." Patient Education and Counseling. 2015.

Submit your next manuscript to BioMed Central and we will help you at every step:

- We accept pre-submission inquiries

- Our selector tool helps you to find the most relevant journal

- We provide round the clock customer support

- Convenient online submission

- Thorough peer review

- Inclusion in PubMed and all major indexing services

- Maximum visibility for your research

Submit your manuscript at www.biomedcentral.com/submit
Biomed Central 